\title{
MINERAL COMPOSITION ANALYSIS OF URINARY STONES USING X-RAY DIFFRACTION AND MICROTOMOGRAPHY
}

\author{
Kuplich, L. ${ }^{1 *}$; Colaço, M. V. ${ }^{1}$; Nogueira, L. P. ${ }^{1}$; Pinto, R. A. S. ${ }^{2}$ C Carrerete, F. B. ${ }^{2}$; Braz, D. ${ }^{3}$; Costa, F. \\ N. ; Droppa Jr, R. ${ }^{4}$; Tromba, G. ${ }^{5}$; Barroso, R. C. ${ }^{1}$ \\ ${ }^{1}$ Departamento de Física Aplicada, UERJ, Rio de Janeiro, RJ, Brasil \\ 2 Departamento de Especialidade Cirurgica, HUPE-UERJ, Rio de Janeiro, RJ, Brasil \\ ${ }^{3}$ Departamento de Engenharia Nuclear, UFRJ, Rio de Janeiro, RJ, Brasil \\ ${ }^{4}$ Centro de Ciências Naturais e Humanas, UFABC, Santo André, SP,Brasil \\ ${ }^{5}$ Sincrotrone Trieste SCpA, Basovizza, Trieste, Italy
}

*lkuplich@gmail.com

\begin{abstract}
Urolithiasis is a metabolic disease, which is characterized by formation of stones (calculi) in urinary tracts, affects a wide sector of population $4-15 \%$ approximately (depending on geographical area). The stones composition can be classified into two parts, an organic matrix and biominerals. Stones are often heterogeneous, containing mainly oxalate, phosphate, and uric acid crystals. The analysis of the mineral composition of urinary stones is an important requirement for a successful management of the disease, which implies not only a proper evaluation and treatment, but also prophylaxis to prevent recurrence. In this work we characterized the mineral composition of human urinary stones from Rio de Janeiro residents using Synchrotron X-ray diffraction (XRD) performed on the regions of interest (ROI) predetermined by microtomography. The results have shown that the calculi are mixed and comprising calcium oxalate monohydrate, calcium oxalate dihydrate, hydroxyapatite and struvite. In this paper, we highlight the presence of struvite, also known as infection stone. The incidence of struvite might be due to the samples being from patients under hospital treatment and / or a particular feature of the residents of Rio de Janeiro.
\end{abstract}

